DOSSIÊ

\title{
A produção científica dos coordenadores do Grupo de Trabalho Currículo da Associação Nacional de Pós-Graduação e Pesquisa em Educação (ANPEd): opções teórico-metodológicas*
}

\section{RESUMO}

Este artigo analisa as perspectivas teórico-metodológicas da produção científica dos coordenadores do Grupo de Trabalho (GT) 12 (Currículo) da Associação Nacional de Pós-Graduação e Pesquisa em Educação (ANPEd) (2000 a 2010) e os impactos dessa produção nos artigos científicos publicados no referido GT. Encontramos em Bourdieu $(1983,2004)$ a ancoragem para a consecução da análise. A maior parte da produção científica examinada tem como quadro de referências a perspectiva pós-crítica. No interior desse campo científico - assimetricamente organizado e estruturado por grupos detentores de maior ou menor capital social e, portanto, em constante disputa pela hegemonia científica -, tal perspectiva alcançou, no período analisado, considerável aceitação. A análise permitiu concluir que os coordenadores do GT são referências para o campo, influenciando o desenvolvimento de novas pesquisas, que oxigenam a produção do conhecimento.

PALAVRAS-CHAVE

currículo; produção científica; autoridade científica.

\footnotetext{
*Este artigo resulta da orientação de um projeto de iniciação científica financiado pela Universidade Federal do Pará (Programa Institucional de Bolsas de Iniciação Científica Pibic/UFPA) realizado no período de 2017 a 2018. É a continuação do estudo que começou em 2013 ao longo do doutoramento em educação que, concluído em 2016, teve como objeto de pesquisa o currículo e as perspectivas teórico-metodológicas na produção dos líderes inscritos no Diretório de Grupos do Conselho Nacional de Desenvolvimento Científico e Tecnológico (CNPq/Brasil).

'Universidade Federal do Pará, Breves, PA, Brasil.
} 
THE SCIENTIFIC COORDINATORS PRODUCTION OF THE WORK GROUP CURRICULUM OF THE NATIONAL ASSOCIATION OF GRADUATE STUDIES AND RESEARCH IN EDUCATION (ANPED): THEORETICAL-METHODOLOGICAL OPTIONS

\begin{abstract}
This article analyzes the theoretical and methodological perspectives of the coordinators scientific production Work Group 12 (Curriculum) of National Association of Graduate Studies and Research In Education (ANPEd) (2000 to 2010) and the impacts of this production on the scientific papers published in the GT. We have found in Bourdieu $(1983,2004)$ the approach to the achievement of the analysis. The majority of the scientific production examined has a postcritical perspective as a frame of reference. In this scientific field - asymmetrically organized and structured by groups with greater or lesser social capital and, therefore, in constant dispute for scientific hegemony - this perspective reached considerable acceptance in the analyzed period. The analysis allowed us to conclude that the GT coordinators are references to the field, influencing the development of new researches that oxygenate the production of knowledge.
\end{abstract}

KEYWORDS

curriculum; scientific production; scientific authority.

\title{
LA PRODUCCIÓN CIENTIIFICA DE LOS COORDINADORES DEL GRUPO DE TRABAJO CURRÍCULO DE LA ASOCIACIÓN NACIONAL DE ESTUDIOS DE POSGRADO E INVESTIGACIÓN EN EDUCACIÓN (ANPED): OPCIONES TEÓRICO-METODOLÓGICAS
}

\section{RESUMEN}

Este artículo analiza las perspectivas teóricas y metodológicas de la producción científica de los coordinadores del Grupo de Trabajo 12 (Currículo) de Asociación Nacional de Estudios de Posgrado e Investigación en Educación (ANPEd) (2000 a 2010) y los impactos de esa producción en los artículos científicos publicados en el GT. Encontramos en Bourdieu $(1983,2004)$ los fundamentos para realizar este análisis. La mayoría de la producción científica examinada tiene una perspectiva poscrítica como marco de referencia. En ese campo científico, organizado y estructurado asimétricamente por grupos con mayor o menor capital social y, por lo tanto, en constante disputa por la hegemonía científica, esta perspectiva alcanzó, en el período analizado, una considerable aceptación. El análisis nos permitió concluir que los coordinadores del GT son referencias al campo, influyendo en el desarrollo de nuevas investigaciones que oxigenan la producción de conocimiento.

PALABRAS CLAVE

currículum; producción científica; autoridad científica. 


\section{INTRODUÇÃO}

Esta pesquisa tem como finalidades analisar as perspectivas teórico-metodológicas da produção científica dos pesquisadores coordenadores do Grupo de Trabalho (GT) Currículo, da Associação Nacional de Pós-Graduação e Pesquisa em Educação (ANPEd), no período compreendido entre 2000 e 2010 e identificar o impacto dessa produção nos artigos científicos aprovados no GT 12 no intervalo de tempo supracitado. Tais finalidades auxiliam a compreender as filiações epistemológicas dos pesquisadores coordenadores do referido GT, permitindo, pois, identificar as matrizes teóricas que têm permeado as produções científicas no campo do currículo.

As questões determinantes da pesquisa encontram-se enunciadas nas seguintes perguntas: quais são as perspectivas teórico-metodológicas presentes na produção científica sobre currículo dos pesquisadores que coordenaram o GT 12 da ANPEd no interstício de 2000 a 2010? Qual é o impacto dessa produção nos artigos científicos aprovados no GT 12 da ANPEd no mesmo período?

A investigação está ancorada nos estudos de Pierre Bourdieu acerca dos processos de formação e organização dos campos sociais. Para Bourdieu (2004, p. 21), "o campo científico é um mundo social e, como tal faz imposições, solicitações, etc., que são, no entanto, relativamente independentes das pressões do mundo social global que o envolve". Ou seja, o campo científico possui normas específicas independentes das exigências do campo social. Por isso, para ocupar um lugar de destaque em um campo científico, é necessário acumular capital científico.

Os campos científico, literário e artístico são considerados por Bourdieu (2004) como mundos sociais que obedecem a leis sociais específicas, constituindo um universo intermediário formado por instituições e agentes que são responsáveis pela difusão da ciência, da literatura e da arte. Fundamentado no pensamento de Bourdieu, afirma Ortiz (1983, p. 21):

O campo científico se particulariza, pois, como um espaço onde se manifestam relações de poder, o que implica afirmar que ele se estrutura a partir da distribuição desigual de um quantum social que determina a posição que um agente específico ocupa em seu seio. Bourdieu denomina esse quantum de "capital social". A estrutura do campo pode ser apreendida tomando-se como referência dois pólos opostos: o dos dominantes e o dos dominados. Os agentes que ocupam o primeiro pólo são justamente aqueles que possuem um máximo de capital social; em contrapartida, aqueles que se situam no pólo dominado se definem pela ausência ou pela raridade do capital social específico que determina o espaço em questão. No caso da ciência, o capital se refere à autoridade científica, a luta que se trava entre os agentes é uma disputa em torno da legitimidade da ciência. Os pesquisadores que desfrutam de posições hierarquicamente reconhecidas como dominantes dispõem de maior capital científico, possuem individualmente maior celeridade e prestígio, mas socialmente detêm ainda o poder de impor, para os outros componentes do grupo.

A posição que o agente social ocupa no interior do campo científico é determinada pelo seu capital social. É esse quantum social que organiza o campo 
científico e define quem ocupará o polo dos dominantes e o dos dominados. Tal estrutura assimétrica gera, entretanto, relações de poder que giram ou em torno da manutenção - no caso daqueles que ocupam uma posição hierarquicamente reconhecida — ou da mudança das posições ocupadas no interior do campo científico.

Pode-se genericamente verificar que quanto mais as pessoas ocupam uma posição favorecida na estrutura, mais elas tendem a conservar ao mesmo tempo a estrutura e sua posição, nos limites, no entanto, de suas disposições (isto é, de sua trajetória social, de sua origem social) que são mais ou menos apropriadas à sua posição. (Bourdieu, 2004, p. 29)

A manutenção da posição no polo dominante do campo científico requer do pesquisador fecunda produção intelectual, ou seja, um investimento permanente em acumulação de capital social, incidindo na concentração de créditos que assegure ao pesquisador reconhecimento e distinção entre os pares concorrentes, por ser o capital científico que fundamenta e organiza as relações entre os agentes no interior do campo.

Conforme afirma Bourdieu (2004, p. 35), o capital científico está fundamentado em dois polos de poder:

Os campos científicos são o lugar de duas formas de poder que correspondem a duas espécies de capital científico: de um lado o poder que se pode chamar de temporal (ou político), poder institucional e institucionalizado que está ligado a ocupação de posições importantes nas instituições científicas [...] e ao poder sobre os meios de produção [...] e de reprodução (poder de nomear e de fazer as carreiras) que ela assegura. De outro, um poder específico, "prestígio" pessoal que é mais ou menos independente do procedente, segundo os campos e as instituições, e que repousa quase exclusivamente sobre o reconhecimento, pouco ou mal objetivado e institucionalizado, do conjunto de pares ou da fração mais consagrada dentre eles.

O reconhecimento do pesquisador dá-se, portanto, mediante a posição por ele ocupada no interior do seu campo de pesquisa. De um lado, esse atributo valorativo está ligado à ocupação de cargos importantes nas instituições científicas (poder temporal ou poder político). De outro lado, o capital científico alberga o tipo de poder denominado de específico ou "puro", que consiste na acumulação, pelo pesquisador, de capital científico objetivado, ou seja, de produção científica.

As duas espécies de capital científico têm leis de acumulação diferentes: o capital científico "puro" adquire-se, principalmente, pelas contribuições reconhecidas ao progresso da ciência, as invenções ou as descobertas (as publicações, especialmente nos órgãos mais seletivos e mais prestigiosos, portanto, aptos a conferir prestígio à moda de bancos de créditos simbólicos, são o melhor indício); o capital científico da instituição se adquire, essencialmente, por estratégias políticas (específicas) que têm em comum o fato de todas exigirem tempo — participação em comissões, bancas (de teses, de concursos), colóquios mais ou menos convencionais no plano científico, cerimônias, reuniões etc. — de modo que é difícil dizer 
se, como o professam habitualmente os detentores, sua acumulação é o princípio (a título de compensação) ou o resultado de um menor êxito na acumulação da forma mais específica legítima do capital científico. (Bourdieu, 2004, p. 36)

Segundo Bourdieu (2004), o capital científico determina as posições dos agentes no campo científico. Nessa acepção, "as posições dominantes no interior do campo científico pertencem àqueles que dispõem de maior capital, maior celeridade ou prestígio" (Garcia, 1996, p. 70).

O jovem que se inicia no campo científico, e que se volta fervorosamente para os estudos, não está simplesmente produzindo conhecimento, mas, sobretudo, investindo num capital cultural, que irá posteriormente assegurar-lhe uma posição dominante no campo dos pesquisadores científicos. (Ortiz, 1983, p. 22)

Pertencer a um campo científico significa ter feito os investimentos necessários para fazer parte daquela comunidade científica, a saber, investir em capital científico, seja por meio da obtenção do poder político, seja pela acumulação de poder específico que lhe permita ser reconhecido pelos seus pares.

Exemplificando: para que alguém possa participar da comunidade científica se faz necessário, a realização de cursos, a ocorrência de publicações, em outros termos, o acúmulo prévio de um certo capital que lhe permita ser reconhecido pelos seus pares como um integrante daquela comunidade. É como um jogo que pressupõe que se reconheçam as suas regras como legítimas e que, fundamentalmente, existam pessoas dispostas a jogar. (Araújo, Alves e Cruz, 2009, p. 36)

O portador de capital científico reveste-se de autoridade científica, de legitimidade para falar em nome da ciência, ou de uma área de conhecimento. "Legitimidade essa socialmente outorgada, geralmente, pelos pares concorrentes, a um agente ou grupo de agentes no interior do próprio campo" (Garcia, 1996, p. 68).

A autoridade científica é definida, por Bourdieu (1983, p. 122), como capacidade técnica e poder social equivalente à competência científica, "compreendida enquanto capacidade de falar e de agir legitimamente (isto é, de maneira autorizada e com autoridade), que é socialmente outorgada a um agente determinado".

Ainda conforme Bourdieu (1983), no campo científico ocorrem disputas concorrenciais em torno do monopólio da autoridade científica. $\mathrm{O}$ interesse por determinada atividade científica contém, implicitamente, o desejo de obtenção de prestígio e reconhecimento científico. Por isso, segundo o autor, todas as práticas têm como finalidade a aquisição da autoridade científica.

Bourdieu (1983, p. 136-137) destaca:

O campo científico é sempre o lugar de uma luta, mais ou menos desigual, entre agentes desigualmente dotados de capital específico e, portanto, desigualmente capazes de se apropriarem do produto do trabalho científico que o conjunto dos concorrentes produz pela sua colaboração objetiva ao colocarem em ação o conjunto dos meios de produção científica disponíveis. Em todo campo se põem, 
com forças mais ou menos desiguais segundo a estrutura da distribuição do capital no campo (grau de homogeneidade), os dominantes, ocupando as posições mais altas na estrutura de distribuição de capital científico, e os dominados, isto é, os novatos, que possuem um capital científico tanto mais importante quanto maior a importância dos recursos científicos acumulados no campo.

Por conseguinte, a posição dos agentes no campo científico é desigualmente distribuída: os dominantes ocupam posições privilegiadas no interior do campo, pois são os detentores de autoridade científica. À vista disso, "os julgamentos sobre a capacidade científica de um estudante ou de um pesquisador estão sempre contaminados, no transcurso de sua carreira, pelo conhecimento da posição que ele ocupa nas hierarquias instituídas" (Bourdieu, 1983, p. 124, grifo do original).

Bourdieu (1983, p. 130) considera a autoridade científica "uma espécie particular de capital que pode ser acumulado, transmitido e até mesmo, em certas condições, reconvertido em outras espécies". Ou seja, os agentes detentores de autoridade científica podem acumular mais capital científico em função do prestígio e do reconhecimento que possuem, além de poder ter acesso a cargos administrativos (capital científico temporal) e de conseguir as mais diversas recompensas, como bolsas de pesquisa, convites, distinções, prêmios, títulos etc.

Partimos de dois pressupostos: o de que os coordenadores do GT 12 possuem capital científico sobre currículo e o da possibilidade de, ao examinarmos a produção dos referidos coordenadores, detectarmos as perspectivas teórico-metodológicas que têm mobilizado os pesquisadores no campo do currículo.

Para analisarmos o capital científico do campo, foi importante fazer as pesquisas bibliográfica e documental. A pesquisa bibliográfica é, segundo Severino (2007, p. 122), fundamental para compreendermos o universo examinado, pois "se realiza a partir do registro disponível, decorrente de pesquisas anteriores, em documentos impressos, como livros, artigos, teses, etc.", oferecendo meios para (re)definirmos o encaminhamento da investigação. Com base no conhecimento acumulado pelas pesquisas anteriores, podemos apresentar os avanços, as lacunas e as fragilidades na produção do conhecimento científico, em determinado campo do saber. Do mesmo modo, tal conhecimento fornece pistas de maneira a traçarmos novas rotas, caminhos ou trajetórias para o desenvolvimento de investigações originais.

A pesquisa documental, por seu turno, constitui uma técnica valiosa de pesquisa, que contribui para complementar "informações obtidas por outras técnicas, seja desvelando aspectos novos de um tema ou problema” (Ludke e André, 1986, p. 38). Para Cellard (2008, p. 295):

É um método de coleta de dados que elimina, ao menos em parte, a eventualidade de qualquer influência - a ser exercida pela presença ou intervenção do pesquisador - do conjunto das interações, acontecimentos ou comportamentos pesquisados, anulando a possibilidade de reação do sujeito à operação de medida.

Por isso, os documentos representam uma fonte primária de informações capaz de evidenciar questões fundamentais para a pesquisa, questões ainda não tematiza- 
das/analisadas por outros estudos. A escolha dos documentos revela-se um desafio para o pesquisador, pois não é um processo aleatório, dado haver "geralmente alguns propósitos, ideias ou hipóteses guiando a sua seleção" (Ludke e André, 1986, p. 40).

A pesquisa documental ocorreu nos sítios hospedados nos bancos de dados do Conselho Nacional de Desenvolvimento Científico e Tecnológico (CNPq), especificamente na Plataforma Lattes, localizada no endereço <http://lattes.cnpq. $\mathrm{br} />$. Nessa plataforma, acessamos o currículo lattes dos coordenadores do GT 12 da ANPEd de modo a analisarmos a produção científica sobre currículo veiculada por meio de artigos científicos.

Pelo CV-Lattes há a possibilidade de se conhecer um pouco mais quem são os pesquisadores, sua produção científica ao longo de sua carreira e também a sua formação e ligação institucional. Ele serve não só como identificação do pesquisador e dos seus trabalhos científicos, mas também é um pré-requisito para se candidatar às bolsas de pesquisa, financiamento de projetos, etc. (Lehfeld, 2007, p. 75)

O currículo lattes constitui importante documento no âmbito da pesquisa acadêmica, pois permite o acesso às informações sobre a produção bibliográfica, técnica e artística/cultural dos pesquisadores brasileiros, bem como às temáticas priorizadas como campo de estudo, contribuindo, assim, com a publicização das pesquisas realizadas e em desenvolvimento e com a institucionalização de campos de conhecimento.

O corpus de análise compreendeu 53 artigos dos pesquisadores que coordenaram o GT Currículo da ANPEd, no período entre 2000 e 2010, e o universo de 158 artigos aprovados no referido GT, no período de incidência da pesquisa. No Brasil, a produção científica do pesquisador é o principal item de mensuração nas avaliações feitas pelas agências de fomento à pesquisa e também de distinção meritocrática, por meio da distribuição de bolsas de produtividade em pesquisa.

\section{A IMPORTÂNCIA DA ANPED NA CONSOLIDAÇÃO DO CURRÍCULO COMO CAMPO DE PESQUISA}

A ANPEd, ao tornar-se o fórum prioritário para a discussão e disseminação da produção científica da área de educação, constitui espaço privilegiado para a divulgação das pesquisas realizadas nos programas de pós-graduação em educação (Sousa e Bianchetti, 2007). Entretanto, além de congregar os programas de pós-graduação, a ANPEd abriga também o pesquisador, denominado de sócio individual. Essa forma de organização permitiu uma interlocução mais ampla com os pesquisadores individuais e com os programas de pós-graduação.

De acordo com Ferraro (2005, p. 53):

Essa foi uma das opções mais felizes e de maior alcance na história da associação. É isso que explica os dois fundamentos sobre os quais se apoiam a ANPEd e as suas práticas: de um lado, a base constituída pelos sócios individuais, pela estrutura de grupos de trabalho, pelas reuniões anuais e regionais, com a preocupação centrada na 
produção e disseminação do conhecimento, dando, por aí, sustentação à pós-graduação (ao ensino e às avaliações externas dos programas); de outro, a base constituída pelos programas de pós-graduação e o Fórum de Coordenadores, com a atenção voltada para a consolidação dos programas e para a participação como atores, não como meros pacientes, nas políticas públicas de pós-graduação e pesquisa, o que se traduz em apoio e benefício da produção e disseminação do conhecimento.

Essas duas bases de sustentação da ANPEd - a direcionada à disseminação do conhecimento, por meio das reuniões anuais e regionais, e aquela voltada à consolidação dos programas de pós-graduação - evidenciam que a associação respondeu de modo particular às interferências do Estado (Sousa e Bianchetti, 2007). Segundo Calazans (apud Ferraro, 2005, p. 51):

É bom recordar - diz ela a propósito da origem da ANPEd - que as associações nacionais de pós-graduação (de todas as áreas) não são instrumentos das políticas de Estado, mas nasceram sob o patrocínio destas [...] em vista das diferentes interpretações que têm sido dadas ao papel do Estado e às iniciativas da sociedade civil na criação de tais entidades. A eleição da primeira diretoria foi disputada no voto, com decisão apertada. É inegável o "patrocínio" estatal. Mas os fundadores e as fundadoras da associação optaram, em sua maioria, na eleição, por uma chapa que queria constituir uma associação identificada mais com a sociedade civil do que com o Estado.

Calazans (apud Ferraro, 2005) refere-se ao papel que o Estado brasileiro exerceu na criação das associações de pesquisa nas diversas áreas do conhecimento, tornando-se o incentivador da organização dessas associações. No caso da ANPEd, desde o início, optou-se por uma gestão identificada com a sociedade civil. Essa escolha, segundo Ferraro (2005), marcou toda a história da ANPEd, propiciando autonomia institucional em relação às agências de fomento à pesquisa. A esse respeito, afirmam Sousa e Bianchetti (2007, p. 395-396):

Merece destaque a atuação da ANPEd na interlocução com a [Coordenação de Aperfeiçoamento de Pessoal de Nível Superior] Capes e com o CNPq. Especificamente em relação à Capes, instância do governo federal responsável, desde 1976, pela avaliação dos programas, têm sido reiterados os questionamentos dos critérios adotados, bem como o encaminhamento de propostas, iniciativas essas que expressam uma dada noção de qualidade da pesquisa e pós-graduação, construída no interior da associação.

Nesse sentido, Maria Malta (apud Sousa e Bianchetti, 2007, p. 393) destaca que, historicamente, a ANPEd tem se tornado um fórum de debate aberto diante da "tensão entre os órgãos do Estado que lidam com a educação e com a pós-graduação, especificamente, e a sociedade civil, sua organização, suas demandas e sua crítica a respeito dos problemas na educação". A ANPEd representa a voz daqueles que defendem a educação pública como direito social, tendo sempre se posicionado de forma crítica, autônoma e contundente diante dos ataques à educação. 
No que diz respeito às reuniões anuais e aos encontros regionais, tais eventos tornaram-se "verdadeiros escoadouros das produções da área" (Ferraro, 2005, p. 65). De acordo com o depoimento de Jacques Therrien reproduzido por Ferraro (2005, p. 65):

A realização de Encontros Regionais de Pesquisa e Pós-graduação, organizados pelos Programas de Pós-Graduação nos moldes dos encontros anuais da ANPEd, permitiu ampla divulgação da produção científica local além de possibilitar maior intercâmbio entre os docentes e pesquisadores. Esses encontros, particularmente nas regiões Norte e Nordeste, tornaram-se fatores que viabilizaram a criação de novos programas, além de facilitarem o acesso à produção científica da área. Com o apoio da [Superintendência do Desenvolvimento do Nordeste] Sudene, ao qual se juntaram o CNPq e a Capes no Seminário de Pesquisa Educacional no Nordeste, realizado em Recife em novembro de 1980, deu-se início aos encontros regionais anuais, o primeiro deles realizado em João Pessoa, em 1981. Posteriormente, esses encontros ocorreram a cada dois anos, chegando ao XVII Encontro, em Belém do Pará, em 2005. Nos mesmos moldes, incentivados nos contextos da ANPEd, as demais regiões brasileiras passaram a realizar encontros regionais, embora com menor frequência, mas com grande participação dos professores, pesquisadores e alunos dos programas de pós-graduação.

Os encontros regionais de pesquisa possibilitaram um intercâmbio maior entre os pesquisadores e favoreceram a circulação da produção científica local. Matos (2016) identificou participação efetiva dos líderes dos grupos de pesquisa do campo do currículo nos encontros regionais. Ao todo, $61 \%$ dos líderes participaram dos referidos encontros, com destaque para o Encontro de Pesquisa Educacional Norte e Nordeste (Epenn), que contabilizou 23\% de participações, seguido da ANPEd Sudeste, com 16\% de participações, e, posteriormente, a ANPEd Centro-Oeste e ANPEd Sul, com $11 \%$ cada uma.

Segundo Sousa e Bianchetti (2007, p. 395-396), o

estímulo à realização dos seminários de pesquisa regionais (as "anpedinhas") causou impacto positivo, criando outros espaços de formação, possibilitando que alunos de pós-graduação pudessem se deslocar mais proximamente e propiciando que sejam atendidas e respeitadas especificidades regionais.

Para Ferraro (2005, p. 67), uma das estratégias que contribuiu para a disseminação das produções científicas dos pesquisadores nas reuniões anuais e regionais foi "a introdução do meio digital para publicação na íntegra dos trabalhos aceitos". A publicação dos trabalhos nos anais dos eventos científicos, seja nos cadernos de resumos, seja o texto integral em CD-ROM e/ou no sítio do evento, contribuiu para a aceitação desses espaços como canais de divulgação das pesquisas científicas.

A apresentação de uma pesquisa (de seus resultados parciais ou finais) em um evento científico denota que a investigação já passou por um processo de avaliação pelos especialistas da área (comitê científico), que conferem legitimidade ao que já foi produzido. É um momento de troca de experiências e de divulgação dos traba- 
lhos que estão em desenvolvimento, permitindo, ainda, identificar as tendências e perspectivas teóricas em evidência nas diversas áreas do conhecimento.

As reuniões anuais da ANPEd são espaços em que circulam os pesquisadores que conquistaram uma posição de destaque no seu campo científico. Por isso, os pesquisadores bem posicionados no campo disputam, nesse espaço, o monopólio da competência científica. "Os campos, enquanto espaços estruturados e hierarquizados são arenas onde são travadas lutas pela conquista de posições e de capital”(Araújo, Alves e Cruz, 2009, p. 36).

A participação dos pesquisadores que representam a autoridade científica do campo, entendida com base em Bourdieu (1983) como legitimidade socialmente outorgada a determinados agentes para falar em nome do campo, significa que esse é um espaço de luta em torno da legitimidade científica.

A luta pela autoridade científica, espécie particular de capital social que assegura um poder sobre os mecanismos constitutivos do campo e que pode ser reconvertido em outras espécies de capital, deve o essencial de suas características ao fato de que os produtores tendem, quanto maior for a autonomia do campo, a só ter como possíveis clientes seus próprios concorrentes. (Bourdieu, 1983, p. 126)

Os produtores particulares de capital científico, particularmente os mais prestigiosos, têm como principais clientes seus próprios concorrentes, pois "somente os cientistas engajados no mesmo jogo detêm os meios de se apropriar simbolicamente da obra científica e de avaliar seus méritos" (Bourdieu, 1983, p. 127). Por isso, eventos como a Reunião Anual da ANPEd são importantes para garantir o monopólio da autoridade científica. Por tal motivo, circular nesse espaço, para os que estão em uma posição dominante no campo, é uma forma de demarcar posição, enquanto para os novatos é uma oportunidade de divulgar sua pesquisa aos pares mais prestigiosos e apropriar-se das ideias que estão em ebulição no campo.

A ANPEd exerceu papel estratégico na constituição e consolidação do campo do currículo, assim como na de outros campos na área da educação. Os GTs, por sua vez, desempenham papel crucial de aglutinamento dos pesquisadores e de definição de política científica e epistemológica (adoção de uma ou mais correntes teóricas, por exemplo). Eles são centrais para entender o jogo de poder no interior do campo. Houve, ao longo dos últimos anos, várias rupturas no GT e disputas significativas fundamentadas em perspectivas teórico-metodológicas.

Para Macedo (2013, grifos do original) ${ }^{1}$, coordenador do GT 12 da ANPEd (GT Currículo):

A produção de conhecimentos no campo do currículo e os debates formativos realizados sobre as questões desse campo no GT 12 [...] se apresenta hoje como um

1 Entrevista especial do Boletim ANPEd com o coordenador do GT 12, o professor Roberto Sidnei Macedo, da Universidade Federal da Bahia (UFBA), analisa a atuação do GT Currículo e sua articulação na ANPEd e na área da educação em âmbito nacional e internacional. Disponível em: http://www.anped.org.br/news/entrevista-roberto-sidnei-macedo-ufba-coordenador-do-gt-12-curriculo. Acesso em: 16 jun. 2018. 
espaço fulcral do pensamento curricular brasileiro, com significativas inserçöes internacionais, dada às relaçôes que seus membros edificam tanto via relaçôes com grupos de pesquisa de países vizinhos, assim como com representantes de vários continentes.

É importante, pois, compreender as filiações epistemológicas dos agentes que coordenam o GT 12 da ANPEd, as rupturas e as perspectivas que estão em circulação dentro do campo. Para Lopes e Macedo (2007,p. 14), "analisar a produção do campo do currículo inclui tomar como objeto o conhecimento produzido por sujeitos investidos da legitimidade de falar sobre currículo". Consideramos que os coordenadores do referido GT são autoridades científicas da área e influenciam na definição do que vem a ser o currículo.

\section{A PRODUÇÃO CIENTÍFICA DOS COORDENADORES DO GRUPO DE TRABALHO CURRÍCULO DA ANPED NO PERÍODO DE 2000 A 2010}

No tempo histórico de abrangência da pesquisa (2000 a 2010), 10 pesquisadores lideraram o GT Currículo da ANPEd: Alice Cassimiro Lopes e Regina Celi Oliveira da Cunha (2000 e 2001); Sandra Corazza e Carlos Eduardo Ferraço (2002 e 2003); Inês Barbosa de Oliveira e Antônio Carlos Amorim (2004 e 2005); Antônio Carlos Amorim e Eurize Pessanha (2006 e 2007); Elizabeth Macedo e Roberto Sidnei Macedo (2008 e 2009); e Carlos Eduardo Ferraço e Carmen Gabriel (2010 e 2011). Nesse período, Antônio Carlos Amorim exerceu a coordenação do GT por dois mandatos: 2004 a 2005 e 2006 a 2007, assim como Carlos Eduardo Ferraço, nos interstícios de 2002 a 2003 e de 2010 a 2011.

Entre os 10 coordenadores, oito possuem atualmente bolsa de produtividade em pesquisa: três são bolsistas $1 \mathrm{~B}$, dois bolsistas $1 \mathrm{C}$, dois bolsistas $1 \mathrm{D}$ e um bolsista nível 2. A bolsa de produtividade é "destinada aos pesquisadores que se destacam entre seus pares, valorizando sua produção científica segundo critérios normativos, estabelecidos pelo CNPq e específicos, pelos Comitês de Assessoramento (CAs) do CNPq" (CNPQ 2015).

Os coordenadores do GT Currículo possuem bolsas de alto nível do CNPq, pois o $\mathrm{CNPq}$, para o enquadramento dos pesquisadores nos níveis da categoria 1 (A, B, C e D), além da excelência na produção científica, na formação de recursos humanos e na liderança de grupos de pesquisa, considera que os pesquisadores demonstrem liderança em sua área de pesquisa.

Para Moreira (2002, p. 83), o GT Currículo reúne os docentes e discentes que se dedicam a pesquisar questões de currículo:

Os mais produtivos autores do campo costumam comparecer às reuniões, fazendo com que o que se passa no GT corresponda, de fato, a uma caixa de ressonância do que se pesquisa sobre currículo no Brasil. Por conseguinte, um estudo sobre o GT pode certamente contribuir para o maior conhecimento do campo no Brasil. Talvez possa também, embora não seja seu propósito central, estimular reflexões sobre a forma como temos conduzido encontros, seminários e congressos na área da educação. (Moreira, 2002, p. 83) 
O GT configura-se, portanto, como um importante espaço de divulgação das pesquisas do campo do currículo no Brasil. Do mesmo modo, constitui-se como fonte para as pesquisas em desenvolvimento no concernente ao referencial teórico-metodológico em evidência das pesquisas desenvolvidas pelos pesquisadores mais produtivos do campo.

Para Bourdieu (1983), a opção por um referencial teórico-metodológico é uma decisão política e está diretamente relacionada à posição que o pesquisador ocupa no campo científico: "Os dominantes são aqueles que conseguem impor uma definição da ciência segundo a qual a realização mais perfeita consiste em ter, ser e fazer aquilo que eles têm, são e fazem" (Bourdieu, 1983, p. 128). Ainda de acordo com Bourdieu (1983, p. 126-127):

Não há "escolha" científica - do campo da pesquisa, dos métodos empregados, do lugar de publicação; ou, ainda, escolha entre uma publicação imediata de resultados parcialmente verificados e uma publicação tardia de resultados plenamente controlados - que não seja uma estratégia política de investimento objetivamente orientada para a maximização do lucro propriamente científico, isto é, a obtenção do reconhecimento dos pares-concorrentes.

O autor, conforme se lê no excerto a seguir, afirma que as escolhas teórico-metodológicas estão direcionadas à aquisição de autoridade científica:

Todas as práticas estão orientadas para a aquisição de autoridade científica (prestígio, reconhecimento, celebridade etc.), o que chamamos comumente de "interesse" por uma atividade científica (uma disciplina, um setor dessa disciplina, um método etc.) tem sempre uma dupla face. $\mathrm{O}$ mesmo acontece com as estratégias que tendem a assegurar a satisfação desse interesse. (Bourdieu, 1983, p. 124)

Em conformidade ainda com Bourdieu (1983), tal interesse orienta a definição de temas, problemas e objetos de pesquisa. Também segundo o autor, "os conflitos epistemológicos são sempre, inseparavelmente, conflitos políticos" (Bourdieu, 1983, p. 124). Ou seja, conflitos que objetivam a manutenção da autoridade científica de determinados agentes.

No que diz respeito aos principais teóricos utilizados como referência pelos coordenadores, podemos destacar: Basil Bernstein, Stephen Ball, Gaston Bachelard, Gilles Deleuze, Michel Foucault, Inês Barbosa de Oliveira, Michel de Certeau, Boaventura de Sousa Santos, Pierre Bourdieu, Antônio Carlos Amorim, Michael Apple, Homi Bhabha, Stuart Hall, Ernesto Laclau, Alice Casimiro Lopes, Roberto Sidnei Macedo e Elizabeth Macedo.

Os autores acionados nas produções científicas dos coordenadores do GT são de diversas perspectivas teóricas, as quais classificamos em três correntes de pensamento hegemônicas: a crítica, a pós-crítica e a que chamamos de híbrida.

O conceito de hibridismo permite vislumbrar novas perspectivas de análise para a compreensão dos processos de reconhecimento, de legitimação, de interpretação e de apropriação das políticas curriculares nas diferentes instâncias pelas quais transitam até à sua efetiva implementação na instância da prática. 
É preciso considerar, entretanto, que sua utilização oferece oportunidades, riscos, ambivalências e possibilidades. (Matos e Paiva, 2007, p. 187)

É claramente notável, porém, que a perspectiva pós-crítica tem maior prevalência na produção dos coordenadores do GT 12 da ANPEd. Muitos deles, ao longo de sua produção científica, passaram por modificações em suas perspectivas teóricas: é possível encontrar, por exemplo, em produções anteriores às do período aqui analisado, trabalhos com predominância de teoria crítica. Há, contudo, certo período em que tem maior espaço entre os pesquisadores a perspectiva pós-crítica. A esse respeito, Lopes (2013, p. 8) diz:

Hoje, no Grupo de Trabalho (GT) Currículo da ANPEd (Associação Nacional de Pós-graduação e Pesquisa em Educação) que reúne as principais lideranças do campo no Brasil, é possível falar de uma hegemonia dos estudos de corte pós-crítico, com preponderância para os trabalhos que focalizam a teoria do discurso de Laclau e Mouffe [...]. Caso fossem investigadas as teses e dissertações, ou mesmo os artigos, talvez essa conclusão fosse diferente, [...] com maior referência ao pensamento crítico. É possível supor, contudo, que cada vez mais esse pensamento é interpelado pelas reflexões pós-críticas, negocia o seu espaço político-acadêmico com tais reflexões, por vezes gerando híbridos teóricos.

Podemos dizer que não é apenas no GT que há prevalência de pesquisas pós-críticas. Tal predominância pode ser observada, também, nas pesquisas dos coordenadores do GT, pois a maioria dos coordenadores tem produzido capital científico sob a perspectiva pós-crítica.

Notamos a existência de uma diversidade de influências teóricas no campo do currículo, as quais contribuíram para a emergência de novos temas, problemas e objetos que ampliaram as possibilidades de análise do campo. Identificamos que, no aspecto metodológico, há um processo de experimentação de novas ferramentas metodológicas para analisar esses objetos.

\section{O IMPACTO DA PRODUÇÃO CIENTÍFICA DOS COORDENADORES DO GRUPO DE TRABALHO CURRÍCULO NOS ARTIGOS CIENTÍFICOS}

Moreira (2002), em "O campo do currículo no Brasil: construção no contexto da ANPEd”, analisa os trabalhos apresentados nas reuniões da ANPEd no período de 1996 a 2000. Ancorado no conceito de campo, de Bourdieu, o autor aborda como vem se constituindo, por meio do Grupo de Trabalho Currículo, da ANPEd, o campo do currículo no Brasil:

O campo tem-se ampliado e diversificado cada vez mais. Produzem-se, com regularidade crescente, teses, dissertações, documentos oficiais, artigos e livros sobre currículo. Faz-se necessário, portanto, analisar mais profundamente esse conjunto de textos para que melhor se compreendam os caminhos seguidos, as tendências, os processos de produção, as conquistas, as lacunas, bem como as possíveis influências na determinação de políticas e de práticas. (Moreira, 2002, p. 83) 
Com base na análise da bibliografia apresentada nos trabalhos investigados, Moreira (2002) observou o predomínio de referências teóricas de especialistas em currículo e de autores do campo da filosofia, da sociologia e dos estudos culturais. Evidenciou, também, que é significativa a presença de autores pós-modernos e pós-estruturalistas. Há, no entanto, escassez de referências a autores associados à psicologia e à antropologia e, sobretudo, relacionados à história, mesmo nos estudos de cunho histórico.

O autor constata, fundamentado no exame dos trabalhos, que há

preocupações com o cotidiano escolar, com a construção do conhecimento em redes, com distintos artefatos culturais, com propostas curriculares, com o multiculturalismo, com o poder de controle e de governo do currículo, bem como com a história do pensamento curricular e das disciplinas. Fortes críticas são explicitamente dirigidas à Didática, a Paulo Freire, à interdisciplinaridade. Não se encontram críticas abertas a outros autores, nacionais e estrangeiros, que se têm dedicado ao estudo de questões de currículo. Pouco se dialoga com as outras áreas pedagógicas, principalmente com a produção brasileira. (Moreira, 2002, p. 93)

O autor considera excessivo o espaço para apresentação de trabalhos no GT da ANPEd, resultando, consequentemente, na secundarização de discussões de problemas educacionais que carecem de atenção, "particularmente os que se incluem na esfera do currículo, que precisam ser mais bem entendidos e atacados" (Moreira, 2002, p. 92).

As temáticas privilegiadas nos artigos científicos englobam diferentes áreas do conhecimento e estão entrecortadas por diversas perspectivas teóricas. Tal hibridismo evidencia a movimentação das "fronteiras" teóricas, bem como a construção de novas relações conceituais. Ambas disputam espaços nas pesquisas e contribuem para a acumulação de prestígio e capital científico para os diferentes sujeitos que circulam no campo do currículo.

As novas abordagens incorporadas às pesquisas permitiram a construção ou de objetos ou de leituras originais dos objetos já problematizados, movimento que permitiu o questionamento das bases teórico-epistemológicas vigentes no campo, contribuindo para a divulgação de novos campos de pesquisa.

No período de 2000 a 2010, foram publicados 164 artigos na reunião anual da ANPEd no GT Currículo²; destes, seis em espanhol. Porém, como nosso objetivo de pesquisa era o impacto da produção científica dos coordenadores do GT Currículo da ANPEd nos artigos científicos do campo do currículo, mais especificamente nos artigos publicados no GT 12, optamos por trabalhar com as produções nacionais. Desse modo, o nosso corpus de análise compreendeu

2 Cumpre esclarecer que os coordenadores de GT da ANPEd não participam do processo de avaliação dos artigos científicos aprovados nos GTs, sendo tal avaliação coordenada pelo Comitê Científico, que tem a responsabilidade de julgar os trabalhos inscritos nos GTs para apresentação nas reuniões anuais da ANPEd. 
o universo de 158 artigos. Verificamos, posteriormente, quais dos 158 artigos acessados citam um ou mais líderes que coordenaram o GT 12 da ANPEd no período de 2000 a 2010.

A coordenadora mais mencionada nos artigos analisados foi Alice Casimiro Lopes - sua produção científica foi utilizada como referência em 39 artigos -, seguida por Sandra Corazza, a qual foi apontada em 28 artigos. Na sequência, com 23 citações, encontra-se a coordenadora Elizabeth Macedo. As três coordenadoras foram citadas em 90 artigos, o que corresponde a $57 \%$ da produção do período.

Sabemos de antemão que as citações bibliográficas, em um trabalho [...] são importantes sinalizações, que indicam não apenas o "ambiente teórico" em que se processam as interpretações acadêmicas, mas também os "circuitos acadêmicos" que as legitimam. (Silva, 2000, p. 144)

No caso dos coordenadores do GT Currículo da ANPEd, o ambiente teórico e os circuitos acadêmicos exerceram papel importante na legitimação das produções científicas. São produções oriundas de espaços institucionais que possuem pesquisas consolidadas na área e que dispõem de uma rede de interlocutores envolvendo pesquisadores, instituições, grupos de pesquisas etc.

Para Romancini (2010), a citação representa um indicador de impacto da produção, de influência do pesquisador, ou instituição. Do mesmo modo, evidencia que os elos que se constroem na pesquisa são importantes para a consolidação de determinados temas, referencial teórico, metodológico, entre outros.

Igualmente, coordenar o GT 12 significa ter realizado investimentos necessários de maneira a compor aquela comunidade científica, a saber, investir em capital científico, quer por meio da obtenção do poder político, quer pela acumulação de poder específico, isto é, da produção científica que lhe permite o reconhecimento dos seus pares.

Acumular capital significa ser produtivo, manter regularidade na produção de conhecimento, contribuir para a inovação e para o avanço do conhecimento científico. O portador de capital científico reveste-se de autoridade científica, de legitimidade para falar em nome da ciência, ou de uma área de conhecimento.

O que comanda os pontos de vista, o que comanda as intervenções científicas, os lugares de publicação, os temas que escolhemos, os objetos pelos quais nos interessamos etc. é a estrutura das relações objetivas entre os diferentes agentes que são [...] os princípios do campo. É a estrutura das relações objetivas entre os agentes que determina o que eles podem e não podem fazer. Ou, mais precisamente, é a posição que eles ocupam nessa estrutura que determina ou orienta [...] suas tomadas de posição. (Bourdieu, 2004, p. 23, grifo do original)

Os veículos de circulação dessa produção são importantes para a definição do lugar que esse pesquisador ocupa no campo científico. Para que o pesquisador ocupe aí um lugar de destaque, faz-se necessária a publicação de suas pesquisas em veículos mais seletivos e prestigiosos. 
A publicação dos artigos dos coordenadores do GT 12 da ANPEd encontra-se distribuída nos periódicos mais conceituados. Assim, os referidos coordenadores publicaram seus artigos, no período analisado, no periódico Educação $\Xi^{\circ}$ Realidade (classificação A1 pelo Qualis-Periódicos, da Capes 2015). Destacam-se, em seguida, as publicações no periódico Currículo sem Fronteiras (Qualis A2) e, posteriormente, no Revista de Educação da Pontifícia Universidade Católica de Campinas (PUC-Campinas), do estrato B2. Os artigos dos coordenadores do GT 12 circulam em 14 periódicos, todos eles classificados no Qualis-Periódicos: três periódicos A1, três A2, dois B1, quatro B2 e dois B4. A circulação da produção científica concentra-se, entretanto, nos periódicos A1 e A2.

A publicação de artigos em periódicos A1 e A2 evidencia que a acumulação de capital científico favorece o acesso aos veículos de divulgação do conhecimento que possuem alta credibilidade. Para Mueller (2000, p. 77-78), "o prestígio individual que se traduz por convites, prêmios, financiamentos dependem bastante da quantidade de trabalhos publicados". Por isso, o investimento em capital científico é importante para o pesquisador que almeja ocupar posições dominantes dentro do campo, e, nesse aspecto, a qualidade dos veículos utilizados na comunicação dos resultados das pesquisas faz-se relevante para o currículo do pesquisador.

\section{CONCLUSÃO}

O exercício da liderança no GT Currículo da ANPEd coloca o pesquisador em evidência no campo. A produção científica desses pesquisadores torna-se referência para a produção do conhecimento. Para Bourdieu (2004), as relações entre os agentes, seus temas e objetos de pesquisa e os lugares de circulação dessa produção científica resultam da estrutura das relações objetivas, ou seja, das lutas concernentes à busca da hegemonia dentro do campo. Nesse aspecto, a posição ocupada pelo pesquisador no campo determinará o seu grau de influência na produção do conhecimento. No caso específico dos coordenadores do GT 12, verificamos que o capital científico político se transforma em capital objetivado por meio das citações das produções dos coordenadores nos artigos aprovados no GT 12.

O campo do currículo no Brasil incorporou diversas perspectivas teórico-metodológicas. É observando aqueles que estão à frente da pesquisa brasileira no campo do currículo - nesse caso, os líderes do GT Currículo da ANPEd - e o que eles produzem que se torna possível compreender o atual cenário nacional do pensamento curricular. É claramente notável que a perspectiva pós-crítica tem maior prevalência na produção dos coordenadores do GT 12 da ANPEd no período analisado, no entanto muitos deles, ao longo de sua produção científica, passaram por modificações em suas perspectivas teóricas. Assim, é possível encontrar, em produções anteriores ao período analisado, trabalhos em que predomina a teoria crítica, muito embora em outro período tenha prevalecido a perspectiva pós-crítica entre os pesquisadores, acentuando que, no interior desse espaço de luta em torno de hegemonia teórica, essa perspectiva alcançou considerável aceitação entre os pesquisadores. 


\section{REFERÊNCIAS}

ARAÚJO, F. M.; ALVES, E. M.; CRUZ, M. P. Algumas reflexões em torno dos conceitos de campo e de habitus na obra de Pierre Bourdieu. Perspectivas da Ciência e Tecnologia, Rio de Janeiro, v. 1, n. 1, p. 31-40,jan.-jun. 2009. Disponível em: https:// revistascientificas.ifrj.edu.br/revista/index.php/revistapct/article/view/14. Acesso em: 16 mar. 2017.

BOURDIEU, P. O campo científico. In: ORTIZ, R. (org.). Pierre Bourdieu: sociologia. São Paulo: Ática, 1983. p. 122-155. (Grandes Cientistas Sociais.)

BOURDIEU, P. Os usos sociais da ciência: por uma sociologia clínica do campo científico. São Paulo: UNESP, 2004.

CELLARD, A. A análise documental. In: POUPART, J. et al. A pesquisa qualitativa: enfoques epistemológicos e metodológicos. Tradução de Ana Cristina Nasser. Petrópolis: Vozes, 2008. p. 295-316.

CONSELHO NACIONAL DE DESENVOLVIMENTO CIENTÍFICO E TECNOLÓGICO (CNPQ). Bolsas individuais no país, RN-028/2015, Anexo III. CNPq, 2015.Disponível em: http://cnpq.br/web/guest/view/-/journal_content/56_IN STANCE_0oED/10157/2958271?COMPANY_ID=10132. Acesso em: 31 jul. 2018. FERRARO, A. R. A ANPEd, a pós-graduação, a pesquisa e a veiculação da produção intelectual na área da educação. Revista Brasileira de Educação, Rio de Janeiro, n. 30, p. 47-69, set.-dez. 2005. Disponível em: http://www.scielo.br/ pdf/rbedu/n30/a05n30.pdf. Acesso em: 18 maio 2017. http://dx.doi.org/10.1590/ S1413-24782005000300005

GARCIA,M.M.A.O campo das produções simbólicas e o campo científico em Bourdieu. Cadernos de Pesquisa, São Paulo, n. 97, p. 64-72, maio 1996. Disponível em: http://www. fcc.org.br/pesquisa/publicacoes/cp/arquivos/414.pdf. Acesso em: 25 mar. 2018.

LEHFELD, N. Metodologia e conhecimento científico: horizontes virtuais. Petrópolis: Vozes, 2007.

LOPES, A. C. Teorias Pós-Críticas, Política e Currículo. Educação, Sociedade \& Culturas, Porto, n. 39, p. 7-23, 2013. Disponível em: https:/www.fpce.up.pt/ciie/sites/ default/files/02.AliceLopes.pdf. Acesso em: 22 ago. 2018.

LOPES, A. C.; MACEDO, E. (orgs.). Currículo da educação básica (1996-2002). Brasília: MEC, INEP, 2007. Disponível em: http://inep.gov.br/ documents/186968/484330/Curr\%C3\%ADculo+da+educação+básica+\%2819962002\%29/333f70dc-9aa3-41d7-bd8c-3622a6ee3c0e?version=1.1. Acesso em: 8 out. 2018.

LUDKE, M.; ANDRÉ, M. E. D. A. Pesquisa em educação: abordagens qualitativas. São Paulo: EPU, 1986.

MATOS, C. C. de. Produção científica e questões teórico-metodológicas dos líderes dos grupos de pesquisa com ênfase no campo do currículo inscritos no diretório de grupos do CNPq/Brasil. 210f. 2016. Tese (Doutorado em Educação) - Universidade Federal do Pará, Belém, 2016. 
MATOS, M. do C. de; PAIVA, E. V. de. Hibridismo e currículo: ambivalências e possibilidades. Currículo sem Fronteiras, v. 7, n.2, p. 185-201, jul./dez.2007. Disponível em: http://www.curriculosemfronteiras.org/vol7iss2articles/matos-paiva.pdf. Acesso em: 24 ago. 2018.

MOREIRA, A. F. O campo do currículo no Brasil: construção no contexto da ANPEd. Cadernos de Pesquisa, São Paulo, n. 117, p. 81-101, nov. 2002. Disponível em: http:// www.scielo.br/pdf/cp/n117/15553.pdf. Acesso em: 24 mar. 2018. http://dx.doi. org/10.1590/S0100-15742002000300005

MUELLER, S. P. M. A ciência, o sistema de comunicação científica e a literatura científica. In: CAMPELLO, B. S.; CENDÓN, B. V. (orgs.). Fontes de informação para pesquisadores e profissionais. Belo Horizonte: UFMG, 2000 p. 21-34.

ORTIZ, R. (org.). Pierre Bourdieu: Sociologia. São Paulo: Ática, 1983.

ROMANCINI, R. O que é uma citação?: a análise de citações na ciência. Intexto, Porto Alegre, v. 2, n. 23, p. 20-35, jul./dez. 2010. Disponível em: https://seer.ufrgs.br/ intexto/article/view/15885/10508. Acesso em: 19 dez. 2018.

SEVERINO, A.J. Metodologia do trabalho científico.23. ed. São Paulo: Cortez,2007. SILVA, V. G. da. O antropólogo e sua magia. São Paulo: Edusp, 2000.

SOUSA, S. Z.; BIANCHETTI, L. Pós-graduação e pesquisa em educação no Brasil: o protagonismo da ANPEd. Revista Brasileira de Educação, Rio de Janeiro, v. 12, n. 36, p. 389-409, set./dez. 2007. Disponível em: http://www.scielo.br/pdf/rbedu/ v12n36/a02v1236.pdf. Acesso em: 27 jan. 2018. http://dx.doi.org/10.1590/S141324782007000300002

\section{SOBRE A AUTORA}

Cleide Carvalho Matos é doutora em educação pela Universidade Federal do Pará (UFPA). Professora da mesma instituição. E-mail: cleidematos@ufpa.br

Recebido em 31 de janeiro de 2019 Aprovado em 23 de julho de 2019 